\title{
Close congruence between Barcode Index Numbers (bins) and species boundaries in the Erebidae (Lepidoptera: Noctuoidea) of the Iberian Peninsula
}

Antonio S. Ortiz $z^{\ddagger}$ Rosa M. Rubio $\neq$, Juan J. Guerrero ${ }^{\ddagger}$, Manuel J. Garre ${ }^{\ddagger}$, Jose Serrano ${ }^{\ddagger}$, Paul D.N. Hebert $\$$, Axel Hausmannl

‡ Universidad de Murcia, Murcia, Spain

$\S$ Biodiversity Institute of Ontario, Guelph, Canada

| Bavarian State Collection of Zoology, München, Germany

Corresponding author: Antonio S. Ortiz (aortiz@um.es)

Academic editor: Bong-Kyu Byun

Received: 26 Jul 2017 | Accepted: 02 Aug 2017 | Published: 08 Aug 2017

Citation: Ortiz A, Rubio R, Guerrero J, Garre M, Serrano J, Hebert P, Hausmann A (2017) Close congruence between Barcode Index Numbers (bins) and species boundaries in the Erebidae (Lepidoptera: Noctuoidea) of the Iberian Peninsula. Biodiversity Data Journal 5: e19840. https://doi.org/10.3897/BDJ.5.e19840

\section{Abstract}

The DNA barcode reference library for Lepidoptera holds much promise as a tool for taxonomic research and for providing the reliable identifications needed for conservation assessment programs. We gathered sequences for the barcode region of the mitochondrial cytochrome c oxidase subunit I gene from 160 of the 176 nominal species of Erebidae moths (Insecta: Lepidoptera) known from the Iberian Peninsula. These results arise from a research project which constructing a DNA barcode library for the insect species of Spain. New records for 271 specimens (122 species) are coupled with preexisting data for 38 species from the Iberian fauna. Mean interspecific distance was $12.1 \%$, while the mean nearest neighbour divergence was $6.4 \%$. All 160 species possessed diagnostic barcode sequences, but one pair of congeneric taxa (Eublemma rosea and Eublemma rietzi) were assigned to the same BIN. As well, intraspecific sequence divergences higher than $1.5 \%$ were detected in four species which likely represent species complexes. This study reinforces the effectiveness of DNA barcoding as a tool for monitoring biodiversity in 
particular geographical areas and the strong correspondence between sequence clusters delineated by BINs and species recognized through detailed taxonomic analysis.

\section{Keywords}

barcode library, CO1, Lepidoptera, DNA barcoding, Spain, Iberian Peninsula, mitochondrial DNA

\section{Introduction}

The Mediterranean peninsulas of Iberia, Italy, and the Balkans are important hotspots of biodiversity (Myers et al. 2000) as they support more genetic and species diversity than higher latitudes in Europe. The Mediterranean biota, however, has been impoverished by human impacts over a long period of time, which have completely transformed the region (Mooney 1988), so that their habitats are now greatly challenged. A variety of taxa including freshwater fishes, amphibians, and lizards show genetic and phylogeographic concordances indicating that the Iberian Peninsula was a refugial region with many endemic species, as would be expected from long-term refugia fostering speciation through divergence of separate lineages (Gómez and Lunt 2007; Hewitt 2011). In fact, Oosterbroek (1994) suggested that the Mediterranean region, together with the Caucasian region and the Far East, are the most species-rich areas of the Palearctic. The insect fauna of the Mediterranean includes about $75 \%$ of the Western Palearctic fauna (Balleto and Casale 1991).

Lepidoptera is one of the most species-rich orders of insects, with some 155,000 described species found in diverse habitats from cooler regions to tropical forests (Pogue 2009, Nieukerken et al. 2011). In the Palearctic region, almost 25,000 species have been described, including some 8,000 species of Macroheterocera belonging to the superfamilies Geometroidea, Drepanoidea, Bombycoidea, Sphingoidea and Noctuoidea (Konstantinov et al. 2009). Among the 1,577 species of macroheterocerans known from the Iberian Peninsula, almost $20 \%$ of Palearctic fauna, 881 species belong to Noctuoidea (Vives 2014) with approximately $5 \%$ of these taxa endemic to this region. Five families (Notodontidae, Erebidae, Nolidae, Euteliidae and Noctuidae) of Noctuoidea are represented with the Erebidae including 176 species (21\%) in the subfamilies Arctiinae (64), Erebinae (40), Eublemminae (21), Lymantriinae (17), Herminiinae (14) and some others (20).

Since DNA barcodes were proposed as a tool for species identification (Hebert et al. 2003), early studies indicated that DNA barcode libraries require comprehensive coverage of known species to enable the identification of newly collected specimens (Ekrem et al. 2007). Many studies have now employed barcodes to monitor lepidopteran biodiversity (e.g.: Janzen et al. 2005, Janzen et al. 2009, Lukhtanov et al. 2009, Dinca et al. 2010, deWaard et al. 2011, Hausmann et al. 2011a, Hausmann et al. 2011b, Hausmann et al. 
2013, Hausmann et al. 2016b, Huemer 2012, Wilson et al. 2013, Huemer et al. 2014, Liu et al. 2014, Zahiri et al. 2014, Miller et al. 2016), solving systematic problems (e.g.: Hajibabaei et al. 2006, Burns et al. 2008, Hausmann 2011, Hausmann et al. 2009a, Hausmann et al. 2009b, Hausmann et al. 2014, Hausmann et al. 2016a, Huemer and Mutanen 2012, Hundsdoerfer et al. 2009, Mutanen et al. 2012) and to detect invasive species (e.g.: Armstrong and Ball 2005, Ball and Armstrong 2006, deWaard et al. 2010, Nagoshi et al. 2011, Mastrangelo et al. 2014). Several studies have shown that $95-100 \%$ of the species in regional faunas can be discriminated with DNA barcodes (Hajibabaei et al. 2006, Hebert et al. 2009, Hausmann 2011, Hausmann et al. 2011a, Hausmann et al. 2011b, Hausmann et al. 2013). Recent work has tested the impact on barcode resolution of expanding from a regional to continental scale (Mutanen et al. 2012, Hausmann et al. 2013, Huemer et al. 2014, Dinca et al. 2015). Barcodes discriminated all 75 Australian species in the family Sphingidae regardless of their collection site (Rougerie et al. 2014), while 1000 species of Lepidoptera shared by Austria and Finland showed a small decline in identification success when identification was based on a barcode records from just one of these locales (Huemer et al. 2014). However, the application of DNA barcoding requires the construction of a complete reference library and the subsequent assessment of its efficacy for discriminating species. Particularly interesting are taxa for which barcode results are discordant with current taxonomy as they may reflect overlooked cryptic species, species that hybridize, cases of synonymy or situations where a secondary barcode marker is required for species diagnosis.

The Iberian macromoth fauna has been well studied taxonomically and ecologically, reflecting its occupation of a peninsular refuge and a bridge between Europe and Northern Africa. This project represents the first in a series that will assemble a DNA barcode library for all macromoth species from the Iberian Peninsula because its species richness and genetic diversity are the highest in Europe.

The present study has the primary goal of providing access to a comprehensive barcode library for the Erebidae species of the Iberian Peninsula. We additionally test how the molecular delineation of $\mathrm{COI}$ (mitochondrial cytochrome $c$ oxidase subunit I) barcode haplotype clusters compares with the morphological species concept are useful tools for assessing biodiversity and indicating the completeness of biotic surveys. Such data releases in the Barcode of Life Datasystem (BOLD) and GenBank help to democratize access to biodiversity information because each barcode record is accompanied by georeferenced data and images of its source specimen (Ratnasingham and Hebert 2007, Janzen et al. 2009, Hebert et al. 2009, Ratnasingham 2016). Ratnasingham and Hebert (2013) recently implemented the Barcode Index Number (BIN) system as a registry for all species records on BOLD. BINs are important when automated recognition performs well for groups whose taxonomy is as accurately known as Lepidoptera because it helps to refine current species determinations based on morphology to accurately assign unknown samples to an existing species in BOLD. However, it also provides a first estimate of species diversity in groups where the taxonomic framework is missing or poor. Although the BIN system is potentially of great importance to taxonomic research, its performance has seen limited examination. 
The specific aims of this study are (a) to present a public data release of DNA barcodes for Iberian Erebidae, (b) to critically analyse intraspecific variation and interspecific distances in the barcode region and how they relate to traditionally recognized species and, (c) to test the correspondence between BINs and traditionally recognized species.

\section{Material and methods}

\section{Sampling}

Specimens were sampled across Spain and the Canary Islands. Permission to collect Lepidoptera in Spain is required both inside and outside nature reserves in all regions. This study considers all 13 subfamilies of Erebidae known from Iberian Peninsula, representing 176 species (Vives 2014 with some modifications and fauna-eu.org accessed at July, 2017). All specimens were identified by the authors, and identifications were confirmed by dissection in all difficult cases. Iberian specimens are deposited in the Research Collection of Animal Biology (RCBA) at the Department of Zoology and Physical Anthropology of the Universidad of Murcia (Spain). Taxonomy and nomenclature of families, genera and species follow Fauna Europaea (Fibiger and Skule 2013). For further details on specimens see Suppl. material 1.

DNA barcodes were obtained by sampling a dry leg from each of a few vouchers per species, trying to include material from all Iberian faunal regions. In total, tissue samples from 271 Iberian specimens (including one Canarian), representing 122 of the species present in the Iberian Peninsula were submitted for analysis. In addition, existing sequence records were included for 38 of the 54 missing species, adding 87 sequences. These samples derived from Germany (67 sequences; 25 species), Italy (13 seqs; 9 spp.) France (2 seqs; 1 sp.), Cyprus, Ethiopia, Hungary, Macedonia and Russia (each 1 seq.; 1 sp.).

\section{DNA Analysis}

PCR amplification and DNA sequencing were performed at the Canadian Centre for DNA Barcoding following standard high-throughput protocols (Ivanova et al. 2006, deWaard et al. 2008), that can be accessed under www.dnabarcoding.ca/pa/ge/research/protocols. PCR amplification with a single pair of primers consistently recovered a 658 bp region near the 5 ' terminus of the mitochondrial cytochrome c oxidase I (COI) gene that included the standard 648 bp barcode region for the animal kingdom (Hebert et al. 2003). All barcoded voucher specimens are listed in Suppl. material 1 and Suppl. material 2. DNA extracts are currently stored at the Canadian Centre for DNA Barcoding. All new sequences were deposited in GenBank according to the data release policy of the International Barcode of Life Project, and accession numbers are given in Suppl. material 1. Complete specimen data including images, voucher deposition, GenBank accession numbers, GPS coordinates, sequence and trace files can easily be accessed in the Barcode of Life Data System (Ratnasingham and Hebert 2007, Ratnasingham 2016) in the dataset DSIBEREBID (https://doi.org/10.5883/DS-IBEREBID). Access has been restricted until 2018 
for a very few species that show deep intraspecific divergences to enable additional studies aimed at clarifying their taxonomic status.

\section{Data Analysis}

Sequence divergences for the barcode region were quantified using the Kimura 2 Parameter distance model, employing the analytical tools in BOLD (BOLD alignment, pairwise deletion). Genetic distances between species are reported as minimum pairwise distances, while intraspecific variation is reported as mean and maximum pairwise distances.

Each specimen with a sequence longer than 500bp (listed in Suppl. material 1, similarities visualized in a Neighbor Joining tree, Suppl. material 4, records analysed in May 2016) automatically gained a BIN assignment on BOLD. BINs are generated using the Refined Single Linkage (RESL) algorithm which employs a three-phased analysis to reach decisions on the number of BINs (= OTUs) in the overall sequence data set on BOLD (Ratnasingham and Hebert 2013). In contrast to some other approaches employed for OTU designation, such as Automatic Barcode Gap Discovery (Puillandre et al. 2012), its outcome is deterministic. It is also much faster than other approaches, such as the generalized mixed Yule-coalescent model (Pons et al. 2006, Fujisawa and Barraclough 2013), a critical requirement for the analysis of large data sets (see Ratnasingham and Hebert 2013 for of algorithm details and comparisons). Because BIN assignments are dynamically updated as new records are added to BOLD, BINs may be merged when genetically intermediate specimens are encountered or split when new records reveal clear structure in the patterns of sequence divergence. A nomenclature system, based on a set of simple rules (Ratnasingham and Hebert 2013), has been implemented in BOLD to make changes in assignments straightforward to trace and easy to understand. Whenever a discrepancy was found between DNA barcode results and a species asignement, the specimen was re-examined to confirm that its identification was correct, and that sequence results were secure.

\section{Results}

\section{Traditional and BIN species delineations}

Sequences were recovered friom 271 of the 304 (89.5\%) specimens. All sequences were longer than $500 \mathrm{bp}$, meeting the length requirement for DNA barcode status (Ratnasingham and Hebert 2007). These results provided coverage for 124 species that were assigned to 127 BINs. Data for 36 more Iberian species were based on specimens from other regions of Europe and Tathorhynchus exsiccata from Ethiopia (see Suppl. material 1). Thus, 360 barcode records were available for 160 species, $90.9 \%$ of the Iberian fauna. As a 307 bp sequence was available for Odice suava, only 16 species lack coverage (see Suppl. material 3). 
The 160 morphological species were assigned to 163 BINs and could be separated into three categories. Most (96.3\%) taxa showed a perfect match between morphological species and BINs (154 species). Four (2.5\%) species were each placed into two BINs, while just two species, Eublemma rosea and its allopatric congener Eublemma rietzi, were merged into the same BIN. However, even in this case, shallow barcode divergence $(2.02 \%)$ allows the discrimination of $E$. rietzi, described in 2010 , from the similar but morphologically separable E. rosea.

Considering all specimens from all species in the 13 subfamilies, Iberian Erebidae showed a mean interspecific genetic distance of $12.1 \%$ (SE $<0.01 ; n=61,901$ comparisons of barcodes $>500 \mathrm{bp}$ ). By comparison, congeneric species averaged $6.7 \%$ divergence (SE $<0.01 ; n=1,831)$, while the mean nearest neighbour divergence was $6.4 \%(n=160)$. Mean and maximum intraspecific variation were $0.6 \%$ and $4.1 \%$ respectively, based upon traditionally delimited species including the four assigned to more than one BIN ( $n=122$ species represented by more than one specimen). By comparison, the mean and maximum intra-BIN variation were $0.21 \%$ and $3.2 \%$ respectively $(n=165$ BINs represented by more than one specimen; $S E=0.01$ ). As a consequence, there was a clear barcode gap for almost all the species (Fig. 1).

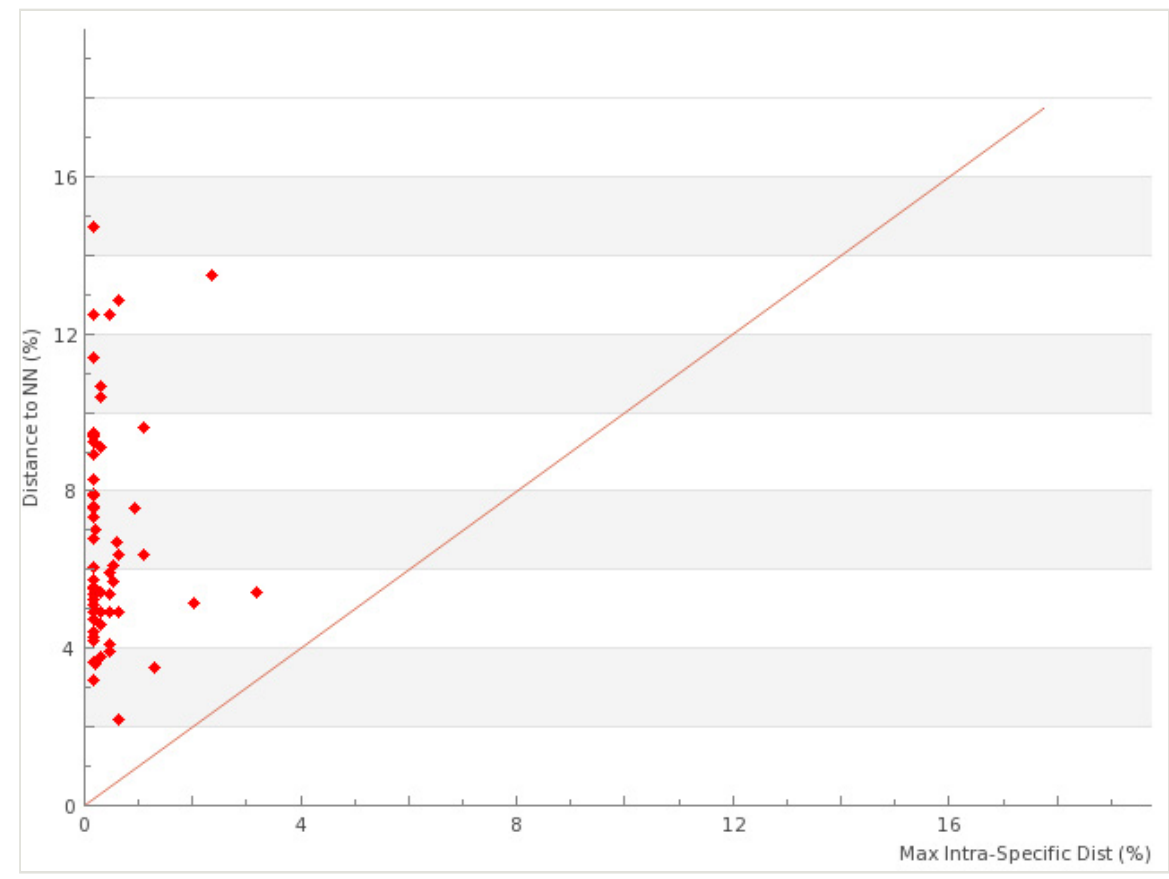

Figure 1. doi

The barcode gap for 121 species of Iberian Erebidae with two or more individuals sampled is shown by plotting maximum intraspecific divergence against nearest-neighbour distance. Points above the diagonal indicate species with a barcode gap. 


\section{Species assigned to multiple BINs}

Although most Iberian Erebidae showed very limited intraspecific barcode variation, 4 of the 160 species (see Suppl. material 1) were placed in two BINs, typically with more than $1.5 \%$ sequence divergence. Maximum sequence divergences between the BINs assigned to a currently recognized species averaged $2.22 \%$, but ranged from $1.61 \%$ to $3.09 \%$. Of the 8 BINs represented, six (75\%) involved a single Iberian specimen distant from the cluster formed by its conspecifics (cf. Suppl. material 1). Interestingly, two of these six singletons involved a haplotype also detected in specimens collected outside the Iberian Peninsula.

Among the four species assigned to more than one BIN, 4 of the 8 intraspecific BIN clusters represent cases where both BINs occur in sympatry as defined by cases where the minimum geographic distance between members of the two BINs was less than 100 $\mathrm{km}$. Two cases of BIN splits corresponded to subspecies recognized by traditional taxonomy: Ocnogyna z. zoraida (BOLD:ACE3052) \& Ocnogyna z. hemigena (Graslin, 1850) (BOLD:AAY5665), and Arctia v. villica (BOLD:ACP7477) \& A. v. angelica (Boisduval, 1829) (BOLD:ABY6789). However, no morphological differences (e.g. wing colour, wing pattern, morphology of genitalia) were evident between members of different BINs in the other two species (Orgyia dubia, Ocnogyna baetica). However, both cases involved geographically isolated lineages with the minimum geographic distance between members of the two BINs being around $125 \mathrm{~km}$ in O. dubia and $330 \mathrm{~km}$ in O. baetica.

\section{Discussion}

\section{Identification accuracy}

Following the definition of 'diagnostic' barcode clusters including those with monophyletic intraspecific splits (Hausmann et al. 2013), DNA barcodes discriminate all of the 160 Erebidae species examined in this study. These results are similar to those reported in other regions; $99 \%$ of the Lepidoptera from north-eastern North America were found to possess diagnostic barcodes (Hebert et al. 2009), 99\% of the butterflies and larger moths of Germany (Hausmann et al. 2011b), $98.8 \%$ of the Lepidoptera species shared by two localities in Finland and Austria (Huemer et al. 2014), 98.5\% of Bavarian geometrids (Hausmann et al. 2011a), 93.1\% of Iberian butterflies (Dinca et al. 2015), 93\% of European geometrids (Hausmann et al. 2013) and 90\% of Romanian butterflies (Dinca et al. 2010).

The success of re-identification by DNA barcoding remains high in Erebidae even when analysis is extended to a European scale. A different pattern with lower number of BINspecies-matches species was reported for European Geometridae (Hausmann et al. 2013) and on a group of European leaf-mining moths (Nieukerken et al. 2012). Interestingly, geographical barcode differentiation played a minor role over distances of up to $2800 \mathrm{~km}$ in north-eastern American Lepidoptera (Hebert et al. 2009) and up to $1600 \mathrm{~km}$ in European Lepidoptera (Huemer et al. 2014) or at general scale in North-American Noctuoidea (Zahiri et al. 2014), and between the Lepidoptera of European Alps, Fennoscandia and North 
America (Mutanen et al. 2012). Although larger sample sizes in Europe may reveal new splits and cases of barcode sharing overlooked in the present study, identification success is unlikely to show a significant decline. In particular, increased sample sizes may raise the incidence of splits, but their detection will not lower the identification success.

\section{Different species assigned to the same BIN}

Just one pair of species shared a BIN, the recently separated Eublemma rosea and $E$. rietzi (Witt and Ronkay 2011). Species pairs placed in a single BIN often show shallow divergences, meaning that DNA barcodes are diagnostic and this was true for these Eublemma. The endemic E. rietzi was described in 2010 from Granada and is only known from a small area between Baza-Cúllar-to north of the Benamaurel village although the authors considered it as Atlanto-Mediterranean corotype. On the other hand, the distribution of $E$. rosea in Europe is surprisingly disjunct between a North-western population in Iberia and the rest in the Alps, southern Italian Peninsula, Slovenia, etc. This case of BIN sharing among allopatric species with slightly divergent genetic clusters suggests that these taxa represent recently separated lineages that are still undergoing genetic differentiation and incipient speciation. The evolution of morphological traits such as genitalia is generally thought to be rapid (Eberhard 1985, Shapiro and Porter 1989, Arnqvist 1998), perhaps faster than COI diversification.

A second potential case of BIN sharing involved the Eilema complana/ pseudocomplana complex as its members were allocated to one or two BINs depending on the taxonomic status of certain Iberian populations. Witt and Ronkay (2011) view E. complana as one of the commonest European Lithosiini, a species showing high variation in its morphology and genital features. One of its lineages, E. c. iberica Mentzer, 1980 was originally described as a subspecies of E. pseudocomplana Daniel, 1939 but was later (Ylla et al. 2010) proposed as a subspecies of $E$. complana based on certain similarities in genital morphology. As well, the presence of a pale ochreous androconial patch on the underside of the forewing suggests a closer relationship between complana and iberica. However, this reduction of the androconial scales may also reflect introgression from the allopatric $E$. pseudocomplana. Our results placed all Iberian specimens of E. complana iberica in a single BIN (BOLD:AAB6846) that included some specimens morphologically identified as E. pseudocomplana, except two specimens from the Pyrenees sharing another BIN (BOL D:ABW5869) with E. pseudocomplana from southern Germany. This pattern suggests that E. complana/pseudocomplana may represent a case of parapatry with a hybrid zone rather than true sympatry, at least in Iberian Peninsula. BIN-sharing must be considered as rare and further studies are required to detect F1 hybrids, introgression events in Iberian populations, or misidentifications revealing problems in current, morphology-based concepts about species identification. These cases of discrepancy reflect instances where the current taxonomic system is likely flawed and revealing species deserving more intensive study. 


\section{One species assigned to two imore BINs}

Because about one fifth (34/160) of the species examined in this study were represented by a single specimen, additional samples, particularly from new geographic areas and habitats will likely reveal new BINs for some Iberian Erebidae. However, the current analysis revealed BIN splits in four species (Rivula sericealis, Eilema sororcula, Coscinia cribraria, Lygephila craccae) represented by singletons show a different haplotype from the rest of the European populations, potentially pointing to taxonomic implications. We detected one species, Ocnogyna baetica, whose Iberian members were assigned to two BINs with divergence greater than $3 \%$, in the same way that Iberian Eublemma parva and Coscinia cribraria singletons present with other conspecific lberian populations, suggesting these require further study.

Other cases of multiple BINs involved taxa whose discrimination is sometimes uncertain. Ocnogyna z. zoraida and O. z. hemigena as well as Arctia v. villica and A. v. angelica each involve a pair of subspecies of uncertain status. Prior studies have detected specimens with intermediate characters in putative hybrid zones suggesting recent speciation with incomplete lineage sorting and introgression. These lineages occur in sympatry, and usually possess consistent differences in external appearance as noted in the literature or that were apparent from our investigation. These correlations may justify the upgrading of these taxa to a species rank though this decision requires further integrated taxonomic study.

In one BIN-split, Orgyia dubia, the two BINs occurred in allopatry. The presence of two barcode lineages in O. dubia ('subspecies splendida Rambur, 1842') with $2.25 \%$ divergence between central and southern populations might reflect divergence that arose when populations were isolated in different glacial refugia during the Pleistocene. Moreover, the Iberian subspecies splendida needs to be compared to the nominotypical $O$. d. dubia Tauscher, 1806 from its type locality in Russia.

The genus Setina is considered taxonomically difficult due to high inter-populational variability in morphology. In our study, Setina flavicans and S. cantabrica showed clear divergence $(2.34 \%)$ although the nearest neighbour for both taxa is $S$. irrorella (Linnaeus, 1758 ) with $1.77 \%$ distance. Current taxonomy views both $S$. cantabrica and S. flavicans (Freina and Witt 1987, Ylla et al. 2010) as distinct species, although Leraut (2006) treated the latter as a synonym of $S$. irrorella, An integrated taxonomic study is needed to clarify relationships within this genus at a European level.

Iberian Chelis species show how DNA barcodes divergences are often correlated with differences in morphology which can easily be overlooked or disputed (Ortiz et al. 2016). In this case, specimens were assigned to three BINs, two endemics $(C$. arragonensis, $C$. cantabrica), and a third matching one of the haplotypes of $C$. maculosa, a species which is widely distributed in Europe. Interestingly, C. cantabrica from the Cantabric Mountains (BOLD: ACE5195) showed closer barcode similarity (98.39\%) to Alpine specimens of $C$. simplonica (Boisduval 1840) (BOLD: ABW6572) at a distance of $1,000 \mathrm{~km}$ than to its congeners in the Iberian Peninsula. The genetic divergences between Iberian C. maculosa, 
C. arragonensis and C. cantabrica reflect frequent scenarios of geographical isolation during the Quaternary (Pleistocene and late Pliocene) in the Iberian Peninsula (Ortiz et al. 2016).

The strong morphological similarity of all specimens in taxa with BIN splits further supports their recent separation although most cases may represent cryptic species complexes. In such cases, taxonomic decisions are often subjective and depend on the choice of species delimitation models, application of species concepts and taxonomic principles, especially when allopatric populations are involved (Mutanen et al. 2012). Subsequent studies need to involve more detailed morphological investigation and the inclusion of nuclear markers to assess alternative explanations for the sequence divergence patterns, such as geographic structure, biased variation induced by Wolbachia (Smith et al. 2012), heteroplasmy (Frey and Frey 2004) or co-amplification of pseudogenes (Song et al. 2008).

\section{Conclusions}

1. Sequences for the barcode region of the mitochondrial $\mathrm{COI}$ gene from 271 specimens (160 species) of Erebidae moths (Insecta: Lepidoptera) from the Iberian Peninsula were gathered, showing a mean interspecific distance of $12.1 \%$, while the mean nearest neighbour divergence was $6.4 \%$.

2. All 160 species possessed diagnostic barcode sequences, but one pair of congeneric taxa were assigned to the same BIN. Intraspecific sequence divergences higher than $1.5 \%$ were detected in four species which likely represent species complexes.

3. This study reinforces the effectiveness of DNA barcoding as a tool for monitoring biodiversity in particular geographical areas and the strong correspondence between sequence clusters delineated by BINs and species recognized through detailed taxonomic analysis.

\section{Acknowledgements}

We are very grateful to the staff at the Canadian Centre for DNA Barcoding for sequence analysis and to many other colleagues involved in the Barcode of Life project (Centre for Biodiversity Genomics, Guelph, Canada) that contributed to this study. We are particularly grateful to Peter Huemer, Rodolphe Rougerie and Enrique Murria for granting access to their projects on BOLD; to Yerai Monasterio (La Rioja), Carlos Antonietty (Seville), Ramón Macià (Barcelona), Carmelo Abad, Aquilino Albaladejo, José de la Calle, Francisco Lencina and José Luis Palacios (Murcia), Pablo Valero and Maite Mójica (Alicante), Félix J. González-Estébanez (León) and Joseph de Freina (Munich) for loaning specimens and valuable comments. Thanks are also due to Pilar de la Rúa, Carlos Ruiz, Alejandro López, Ana Isabel Asensio and Carmelo Andújar for their comments, suggestions and technical support. 
This study was supported by the project on insect barcoding CGL2009-10906 of the Spanish Ministry of Research and Science and by Regional Excellence 19908-GERM-15 project of the Fundación Seneca (Regional Government of Murcia, Spain). DNA sequencing was supported by Genome Canada through Ontario Genomics in the framework of the iBOL program. Collecting permits were issued by every Regional Administration and support was provided by environmental staff in each of them.

\section{Hosting institution}

Universidad de Murcia, Murcia, Spain

\section{Ethics and security}

No ethical principles were violated when performing this study.

\section{Author contributions}

A.O., J.S., and P.H. obtained funding. A.O., R.R., J.G., M.G. and A.H. collected the samples. A.O., R.R. and A.H. conceived and designed the experiments. A.O., R.R. and A.H. analysed the data. A.O., R.R., A.H. and P.H. wrote the manuscript. J.G., M.G. and J.S. contributed (additions/corrections) to the manuscrpt.

\section{Conflicts of interest}

The authors declare no conflict of interests concerning this study.

\section{References}

- $\quad$ Armstrong KF, Ball SL (2005) DNA barcodes for biosecurity: invasive species identification. Philosophical Transactions of the Royal Society B: Biological Sciences 360 (1462): 1813-1823. https://doi.org/10.1098/rstb.2005.1713

- Arnqvist G (1998) Comparative evidence for the evolution of genitalia by sexual selection. Nature 393: 784-786. https://doi.org/10.1038/31689

- $\quad$ Balleto E, Casale A (1991) Mediterranean insect conservation. In: Collins NM, Thomas JA (Eds) The Conservation of Insects and their Habitats. Academic Press, London, 121-142 pp. https://doi.org/10.1016/b978-0-12-181370-3.50012-9

- Ball SL, Armstrong KF (2006) DNA barcodes for insect pest identification: a test case with tussock moths (Lepidoptera: Lymantriidae). Canadian Journal of Forest Research 36 (2): 337-350. https://doi.org/10.1139/x05-276 
- $\quad$ Burns JM, Janzen DH, Hajibabaei M, Hallwachs W, Hebert PDN (2008) DNA barcodes and cryptic species of skipper butterflies in the genus Perichares in Area de Conservacion Guanacaste, Costa Rica. Proceedings of the National Academy of Sciences 105: 6350-6355. https://doi.org/10.1073/pnas.0712181105

- deWaard J, Hebert PN, Humble L (2011) A comprehensive DNA barcode library for the looper moths (Lepidoptera: Geometridae) of British Columbia, Canada. PLoS ONE 6 (3): e18290. https://doi.org/10.1371/journal.pone.0018290

- deWaard J, Mitchell A, Keena M, Gopurenko D, Boykin L, Armstrong K, Pogue M, Lima J, Floyd R, Hanner R, Humble L (2010) Towards a global barcode library for Lymantria (Lepidoptera: Lymantriinae) tussock moths of biosecurity concern. PLoS ONE 5 (12): e14280. https://doi.org/10.1371/journal.pone.0014280

- $\quad$ deWaard JR, Ivanova NV, Hajibabaei M, Hebert PDN (2008) Assembling DNA barcodes: Analytical Protocols. In: Martin C (Ed.) Methods in Molecular Biology: Environmental Genetics. Humana Press, Totowa, NJ, 275-293 pp.

- Dinca V, Zakharov EV, Hebert PDN, Vila R (2010) Complete DNA barcode reference library for a country's butterfly fauna reveals high performance for temperate Europe. Proceedings of the Royal Society B: Biological Sciences 278: 347-355. https:// doi.org/10.1098/rspb.2010.1089

- Dinca V, Montagud S, Talavera G, Hernández-Roldán J, Munguira M, García-Barros E, Hebert PN, Vila R (2015) DNA barcode reference library for Iberian butterflies enables a continental-scale preview of potential cryptic diversity. Scientific Reports 5 (12395):

1-12. https://doi.org/10.1038/srep12395

- Eberhard GW (1985) Sexual selection and animal genitalia. Harvard University Press, Cambridge, MA, 244 pp.

- $\quad$ Ekrem T, Willassen E, Stur E (2007) A comprehensive DNA sequence library is essential for identification with DNA barcodes. Molecular Phylogenetics and Evolution 43 (2): 530-542. https://doi.org/10.1016/j.ympev.2006.11.021

- $\quad$ Fibiger M, Skule B (2013) Fauna Europaea: Erebidae. Fauna Europaea version 2.5. https://fauna-eu.org/. Accessed on: 2017-7-01.

- Freina JJ, Witt TJ (1987) Die Bombyces und Sphinges der Westpalaerktis (Insecta, Lepidoptera) Band 1. Forschung \& Wissenschaft, München, Germany, 708 pp. [In German].

- $\quad$ Frey JE, Frey B (2004) Origin of intra-individual variation in PCR-amplified mitochondrial cytochrome oxidase I of Thrips tabaci (Thysanoptera: Thripidae): mitochondrial heteroplasmy or nuclear integration? Hereditas 140: 92-98. https://doi.org/10.1111/ j.1601-5223.2004.01748.x

- Fujisawa T, Barraclough T (2013) Delimiting species using single-locus data and the Generalized Mixed Yule Coalescent Approach: a revised method and evaluation on simulated data sets. Systematic Biology 62 (5): 707-724. https://doi.org/10.1093/sysbio/ syt033

- Gómez A, Lunt D (2007) Refugia within refugia: atterns of phylogeographic concordance in the Iberian Peninsula. In: Weiss S, Ferrand N (Eds) Phylogeography of Southern European Refugia. Springer, Dordrecht, Netherlands, 155-188 pp. https:// doi.org/10.1007/1-4020-4904-8 5

- Hajibabaei M, Janzen DH, Burns JM, Hallwachs W, Hebert PDN (2006) DNA barcodes distinguish species of tropical Lepidoptera . Proceedings of the National Academy of Sciences 103: 968-971. https://doi.org/10.1073/pnas.0510466103 
- Hausmann A (2011) An integrative taxonomic approach to resolving some difficult questions in the Larentiinae of the Mediterranean region (Lepidoptera, Geometridae). Mitteilungen der Münchner Entomologischen Gesellschaft 101: 73-97.

- Hausmann A, Haszprunar G, Hebert PN (2011) DNA barcoding the geometrid fauna of Bavaria (Lepidoptera): successes, surprises, and questions. PLoS ONE 6 (2): e17134. https://doi.org/10.1371/journal.pone.0017134

- Hausmann A, Parisi F, Sciarretta A (2014) The geometrid moths of Ethiopia I: tribes Pseudoterpnini and Comibaenini (Lepidoptera: Geometridae, Geometrinae). Zootaxa 3768: 460-468. https://doi.org/10.11646/zootaxa.3768.4.4

- Hausmann A, Sciarretta A, Parisi F (2016) The Geometrinae of Ethiopia II: Tribus Hemistolini, genus Prasinocyma (Lepidoptera: Geometridae, Geometrinae). Zootaxa 4065 (1): 1-63. https://doi.org/10.11646/zootaxa.4065.1.1

- Hausmann A, Sommerer M, Rougeri R, Hebert PDN (2009) Hypobapta tachyhalotaria n. sp. from Tasmania - an example of a new species revealed by DNA barcoding (Lepidoptera, Geometridae). Spixiana 32: 237-242.

- Hausmann A, Haszprunar G, Segerer A, Speidel W, Behounek G, Hebert P (2011) Now DNA-barcoded: the butterflies and larger moths of Germany. Spixiana 34: 47-58.

- Hausmann A, Hebert PN, Mitchell A, Rougerie R, Sommerer M, Edwards T, Young C (2009) Revision of the Australian Oenochroma vinaria Guenée, 1858 species-complex (Lepidoptera: Geometridae, Oenochrominae): DNA barcoding reveals cryptic diversity and assesses status of type specimen without dissection. Zootaxa 2239: 1-21.

- Hausmann A, Miller SE, Holloway JD, deWaard JR, Pollock D, Prosser SWJ, Hebert PDN (2016) Calibrating the taxonomy of a megadiverse insect family: 3000 DNA barcodes from geometrid type specimens (Lepidoptera, Geometridae). Genome 59 (9): 671-684. https://doi.org/10.1139/gen-2015-0197

- Hausmann A, Godfray HCJ, Huemer P, Mutanen M, Rougerie R, van Nieukerken EJ, Ratnasingham S, Hebert PDN (2013) Genetic patterns in European geometrid moths revealed by the Barcode Index Number (BIN) system. PloS ONE 8 (12): e84518. https:// doi.org/10.1371/journal.pone.0084518

- Hebert PDN, deWaard JR, Landry J- (2009) DNA barcodes for 1/1000 of the animal kingdom. Biology Letters 6 (3): 359-362. https://doi.org/10.1098/rsbl.2009.0848

- Hebert PDN, Cywinska A, Ball SL, deWaard JR (2003) Biological identifications through DNA barcodes. Proceedings of the Royal Society B: Biological Sciences 270 (1512):

313-321. https://doi.org/10.1098/rspb.2002.2218

- Hewitt G (2011) Mediterranean peninsulas: the evolution of hotspots. In: Zachos FE, Habel JC (Eds) Biodiversity Hotspots. Springer-Verlag, Berlin, Germany, 123-147 pp. https://doi.org/10.1007/978-3-642-20992-5 7

- Huemer P (2012) Barcoding Lepidoptera of the Alps: the search for cryptic diversity. Barcode Bulletin 3: 4.

- Huemer P, Mutanen M (2012) Taxonomy of spatially disjunct alpine Teleiopsis albifemorella s. lat. (Lepidoptera: Gelechiidae) revealed by molecular data and morphology - how many species are there? Zootaxa 3580: 1-23.

- Huemer P, Mutanen M, Sefc K, Hebert PN (2014) Testing DNA barcode performance in 1000 species of European Lepidoptera: large geographic distances have small genetic impacts. PLoS ONE 9 (12): e115774. https://doi.org/10.1371/journal.pone.0115774

- Hundsdoerfer A, Rubinoff D, Attié M, Wink M, Kitching I (2009) A revised molecular phylogeny of the globally distributed hawkmoth genus Hyles (Lepidoptera: Sphingidae), 
based on mitochondrial and nuclear DNA sequences. Molecular Phylogenetics and Evolution 52: 852-865. https://doi.org/10.1016/j.ympev.2009.05.023

- Ivanova NV, DeWaard JR, Hebert PDN (2006) An inexpensive, automation-friendly protocol for recovering high-quality DNA. Molecular Ecology Notes 6: 998-1002. https:// doi.org/10.1111/j.1471-8286.2006.01428.x

- Janzen DH, Hajibabaei M, Burns JM, Hallwachs W, Remigio E, Hebert PDN (2005) Wedding biodiversity inventory of a large and complex Lepidoptera fauna with DNA barcoding. Philosophical Transactions of the Royal Society B: Biological Sciences 360 (1462): 1835-1845. https://doi.org/10.1098/rstb.2005.1715

- Janzen DH, Hallwachs W, Blandin P, Burns JM, Cadiou J, Chacon I, Dapkey T, Deans AR, Epstein ME, Espinoza B, Franclemont JG, Haber WA, Hajibabaei M, Hall JPW, Hebert PDN, Gauld ID, Harvey DJ, Hausmann A, Kitching IJ, Lafontaine D, Landry J, Lemaire C, Miller JY, Miller JS, Miller L, Miller SE, Montero J, Munroe E, Green SR, Ratnasingham S, Rawlins JE, Robbins RK, Rodriguez JJ, Rougerie R, Sharkey MJ, Smith MA, Solis MA, Sullivan JB, Thiaucourt P, Wahl DB, Weller SJ, Whitfield JB, Willmott KR, Wood DM, Woodley NE, Wilson JJ (2009) Integration of DNA barcoding into an ongoing inventory of complex tropical biodiversity. Molecular Ecology Resources 9 Suppl s1: 1-26. https://doi.org/10.1111/j.1755-0998.2009.02628.x

- Konstantinov A, Korotyaev B, Volkovitsh M (2009) Insect biodiversity in the Palearctic Region. In: Foottit R, Adler P (Eds) Insect Biodiversity. Blackwell, Oxford, UK, 107-162 pp. https://doi.org/10.1002/9781444308211.ch7

- $\quad$ Leraut P (2006) Moths of Europe, vol. 1: Saturnids, Lasiocampids, Hawkmoths, Tiger Moths,... NAP Editions, Verrières-le-Buisson, France, 400 pp.

- $\quad$ Liu X, Yang C, Han H, Ward R, Zhang A (2014) Identifying species of moths (Lepidoptera) from Baihua Mountain, Beijing, China, using DNA barcodes. Ecology and Evolution 4 (12): 2472-2487. https://doi.org/10.1002/ece3.1110

- Lukhtanov VA, Sourakov A, Zakharov EV, Hebert PDN (2009) DNA barcoding Central Asian butterflies: increasing geographical dimension does not significantly reduce the success of species identification. Molecular Ecology Resources 9 (5): 1302-1310. https://doi.org/10.1111/j.1755-0998.2009.02577.x

- $\quad$ Mastrangelo T, Paulo DF, Bergamo LW, Morais EGF, Silva M, Bezerra-Silva G, AzeredoEspin AML (2014) Detection and genetic diversity of a heliothine invader (Lepidoptera: Noctuidae) from north and northeast of Brazil. Journal of Economic Entomology 107 (3): 970-980. https://doi.org/10.1603/EC13403

- $\quad$ Miller S, Hausmann A, Hallwachs W, Janzen D (2016) Advancing taxonomy and bioinventories with DNA barcodes. Philosophical Transactions of the Royal Society B: Biological Sciences 371 (1702): 20150339. https://doi.org/10.1098/rstb.2015.0339

- Mooney HA (1988) Lessons from Mediterranean-climate regions. In: Wilson EO (Ed.) Biodiversity. National Academic Press, Washington, DC, USA, 157-165 pp.

- Mutanen M, Hausmann A, Hebert P, Landry J, de Waard J, Huemer P (2012) Allopatry as a Gordian knot for taxonomists: patterns of DNA barcode divergence in Arctic-Alpine Lepidoptera. PLoS ONE 7: e47214. https://doi.org/10.1371/journal.pone.0047214

- Myers N, Mittermeier R, Mittermeier C, daFonseca GAB, Kent J (2000) Biodiversity hotspots for conservation priorities. Nature 403: 853-858. https://

doi.org/10.1038/35002501 
- $\quad$ Nagoshi RN, Brambila J, Meagher RL (2011) Use of DNA barcodes to identify invasive armyworm Spodoptera species in Florida. Journal of Insect Science 11 (1): 154. https:// doi.org/10.1673/031.011.15401

- $\quad$ Nieukerken Ev, Doorenweerd C, Stovkis FR, Groenenberg DS (2012) DNA barcoding of the leaf-mining moth subgenus Ectoedemia s. str. (Lepidoptera, Nepticulidae) with COI and EF1-a: two are better than one in recognizing cryptic species. Contributions to Zoology 81: 1-24.

- $\quad$ Nieukerken Ev, Kaila L, Kitching IJ, et al (2011) Order Lepidoptera Linnaeus, 1758. In: Zhang, Z.-Q. (Ed.) Animal biodiversity: an outline of higher-level classification and survey of taxonomic richness. Zootaxa 3148: 212-221.

- Oosterbroek P (1994) Biodiversity of the Mediterranean region. In: Forey PI, Humphries CJ, Vane-Wright RI (Eds) Systematics and conservation evaluation. Systematics Association Special Volume No. 50. Clarendon Press, Oxford, UK, 289-307 pp.

- Ortiz AS, Rubio RM, Guerrero JJ, Garre M, Hausmann A (2016) Integrated taxonomy, phylogeography and conservation in the genus Chelis Rambur, [1866] in the Iberian Peninsula (Lepidoptera: Erebidae: Arctiinae). Spixiana 39: 273-286.

- $\quad$ Pogue M (2009) Biodiversity of Lepidoptera . In: Foottit RG, Adler PH (Eds) Insect Biodiversity. Blackwell Publishing, London, UK, 325-355 pp. https:// doi.org/10.1002/9781444308211.ch13

- Pons J, Barraclough TG, Gomez-Zurita J, Cardoso A, Duran DP, Hazell S, Kamoun S, Sumlin WD, Vogler AP (2006) Sequence-based species delimitation for the DNA taxonomy of undescribed insects. Systematic Biology 55: 595-609. https:// doi.org/10.1080/10635150600852011

- $\quad$ Puillandre N, Lambert A, Brouillet S, Achaz G (2012) ABGD, Automatic Barcode Gap Discovery for primary species delimitation. Molecular Ecology 21: 1864-1877. https:// doi.org/10.1111/j.1365-294X.2011.05239.x

- Ratnasingham S (2016) BOLD Barcode of Life Data System, version 3. http:// www.boldsystems.org. Accessed on: 2017-7-01.

- Ratnasingham S, Hebert PDN (2007) BARCODING: bold: The Barcode of Life Data System (http: // www. barcodinglife. org). Molecular Ecology Notes 7: 355-364. https:// doi.org/10.1111/j.1471-8286.2007.01678.x

- Ratnasingham S, Hebert PN (2013) A DNA-based registry for all animal species: the Barcode Index Number (BIN) system. PLoS ONE 8: e66213. https://doi.org/10.1371/ journal.pone.0066213

- $\quad$ Rougerie R, Kitching I, Haxaire J, Miller S, Hausmann A, Hebert PN (2014) Australian Sphingidae - DNA Barcodes Challenge Current Species Boundaries and Distributions. PLoS ONE 9: e101108. https://doi.org/10.1371/journal.pone.0101108

- Shapiro AM, Porter AH (1989) The lock-and-key hypothesis: evolutionary and biosystematic interpretation of insect genitalia. Annual Review of Entomology 34: 231-245. https://doi.org/10.1146/annurev.en.34.010189.001311

- $\quad$ Smith MA, Bertrand C, Crosby K, Eveleigh ES, Fernandez-Triana J, Fisher BL, Gibbs J, Hajibabaei M, Hallwachs W, Hind K, Hrcek J, Huang D, Janda M, Janzen DH, Li Y, Miller SE, Packer L, Quicke D, Ratnasingham S, Rodriguez J, Rougerie R, Shaw MR, Sheffield C, Stahlhut JK, Steinke D, Whitfield J, Wood M, Zhou X (2012) Wolbachia and DNA barcoding insects: patterns, potential, and problems. PloS one 7: e36514. https:// doi.org/10.1371/journal.pone.0036514 
- $\quad$ Song H, Buhay JE, Whiting MF, Crandall KA (2008) Many species in one: DNA barcoding overestimates the number of species when nuclear mitochondrial pseudogenes are coamplified. Proceedings of the National Academy of Sciences 105 (36): 13486-13491. https://doi.org/10.1073/pnas.0803076105

- Vives A (2014) Catálogo sistemático y sinonímico de los Lepidoptera de la Península Ibérica, de Ceuta, de Melilla y de las islas Azores, Baleares, Canarias, Madeira y Salvajes (Insecta: Lepidoptera). Suplemento de SHILAP Revista de Lepidopterología, $1184 \mathrm{pp}$.

- Wilson J, Sing K, Sofian-Azirun M (2013) Building a DNA barcode reference library for the true butterflies (Lepidoptera) of Peninsula Malaysia: what about the subspecies? PloS one 8: e79969. https://doi.org/10.1371/journal.pone.0079969

- Witt TJ, Ronkay L (2011) Noctuidae Europaeae. Lymantrinae-Arctiinae, including Phylogeny and Check List of the Quadrifid Noctuoidea of Europe. Volume 13. Entomological Press, Soro, Denmark, 448 pp.

- $\quad$ Ylla J, Macià R, Gastón FJ (2010) Manual de identificación y guía de campo de los Árctidos de la Península lbérica y Baleares. Argania editio, Barcelona, Spain, 290 pp.

- Zahiri R, Lafontaine JD, Schmidt BC, Dewaard JR, Zakharov EV, Hebert PDN (2014) A transcontinental challenge-a test of DNA barcode performance for 1,541 species of Canadian Noctuoidea (Lepidoptera). PloS ONE 9: e92797. https://doi.org/10.1371/ journal.pone.0092797

\section{Supplementary materials}

\section{Suppl. material 1: Accesion numbers and BINs doi}

Authors: Ortiz, Rubio, Guerrero, Garre

Data type: Genomic data

Brief description: List of species names, sample-IDs, process-IDs (from BOLD database), COI-5P bps, BINs, GenBank Accession numbers, collection country, and Institution storing vouchers. Abbreviations: BIN = Barcode Index Number. NST = Naturmuseum Suedtirol. PCEM = Private Collection of Enrique Murria Beltran. RCAH = Research Collection of Alfred Haslberger. RCBA-UMU = Research Collection Biologia Animal-Universidad de Murcia. RCBD = Research Collection of Bernard Dardenne. RCCZ = Research Collection of Christian Zehentner. RCPL = Research Collection of Peter Lichtmannecker. RCRS = Research Collection of Ralph Sturm. RCTG $=$ Research Collection of Theo Gruenewald. TLF = Tiroler Landesmuseum Ferdinandeum . ZSM = Zoologische Staatssammlung Muenchen.

Filename: Appendix S1.pdf - Download file (102.87 kb)

\section{Suppl. material 2: Systematic list of subfamilies and species, barcode gap analysis (Mean and Maximum intraspecific variation and distance to nearest neighbor NN) for 160 Iberian species in the all European Erebidae doi}

Authors: Ortiz, Rubio, Guerrero, Garre

Data type: Genetic diversity data

Brief description: Systematic list of subfamilies and species, barcode gap analysis (Mean and Maximum intraspecific variation and distance to nearest neighbor NN) for 160 lberian species in the all European Erebidae 
Filename: Appendix S2.pdf - Download file (96.73 kb)

\section{Suppl. material 3: List of 16 Iberian taxa without a BIN assignment doi}

Authors: Ortiz, Rubio, Guerrero, Garre

Data type: Species list

Brief description: List of 16 Iberian taxa without a BIN assignment (awaiting DNA barcoding); a species with short sequences are marked with an *.

Filename: Appendix S3.pdf - Download file (92.25 kb)

\section{Suppl. material 4: BOLD TaxonID Tree doi}

Authors: Ortiz, Rubio, Guerrero, Garre

Data type: Image

Brief description: Genetic similarities visualized in a Neighbor Joining tree

Filename: Appendix S4.pdf - Download file (22.08 kb) 